\title{
A study of interval breast cancer within the NHS breast screening programme
}

\author{
W K Cowan, B Angus, J C Gray, L G Lunt, S Ramedan Al-Tamimi
}

\begin{abstract}
Aim-To define the biological nature and malignant potential of interval cancers presenting to a breast unit within the NHS breast screening programme.

Methods-112 interval cancers were compared with matched, screen detected and symptomatic cancers in terms of their radiographic, histopathological, and immunohistochemical features.

Results-Interval cancers, strictly defined, showed no characteristic radiographic pattern. In terms of size, vascular invasion, lymph node status, and prognosis they were intermediate between screen detected and symptomatic cancers. Within the interval cancers there was an excess of grade 1 and grade 3 tumours, and lesions with a high Ki67 index but immunohistochemistry otherwise failed to discriminate between the three groups. Inclusion of data from false negative "interval cancers" did not significantly alter the results.

Conclusions-Interval cancers are more aggressive than screen detected cancers but in general less aggressive than symptomatic cancers. However, within a heterogeneous group, occasional interval cancers are exceptionally malignant.

(F Clin Pathol 2000;53:140-146)
\end{abstract}

Keywords: breast cancer screening; interval cancer

Studies of mammary cancers surfacing in the intervals between screening episodes are of obvious value in measuring the quality of the screening procedure. If these tumours are a set of fast growing, aggressive lesions then perhaps more frequent screening would be worthwhile. Several studies have yielded conflicting opinions on the nature of these tumours, some believing that they carry a poor prognosis, ${ }^{1}$ whereas others maintain that they are no more aggressive than screen detected tumours and that their singular feature is merely the difficulty that they pose in diagnosis. ${ }^{2}$ These opposing views are perhaps in part the result of differing definitions and screening methodology, but despite these reservations the essential nature of interval cancers may emerge as more units record their experience. Studies of interval cancers within the NHS breast screening programme (NHSBSP) have been more concerned with screening practices than with histopathology, and immunohistochemistry has been neglected. In an effort to clarify the nature of our interval cancers we report here a series presenting to one unit within the
NHSBSP. We have compared their radiographic and histopathological features as well as their expression of antigens of potential prognostic significance with those of other symptomatic cancers and with screen detected lesions. The antigens selected for investigation were c-erbB-2 protein, oestrogen and progesterone receptors, NM23, Ki67, p53, and the p53 binding protein MDM2, each of which has been shown to be of potential prognostic significance in breast cancer. ${ }^{3-8}$

\section{Methods}

DEFINITION OF INTERVAL CANCERS

The screening interval within the NHSBSP is three years, and interval cancers are by definition tumours presenting symptomatically within three years of the last screen.

The identification and definition of interval cancers within the Northern Region of the NHSBSP has already been set out ${ }^{9}$ but may be summarised as follows. The names and dates of birth of every patient diagnosed histopathologically as having breast cancer throughout the region are collated centrally and a combined list is circulated monthly to each of the four breast screening centres in the region. Here the names are checked against those of women who have been screened, and interval cancers identified. The population of the region is relatively stable and of the few diagnosed outside its boundary and escaping the initial search, some are found by further inquiry.

After the screening mammograms, mixed randomly with negative films, have been reviewed blind by at least six independent radiologists, the final stage is a general discussion at the Regional Quality Assurance Centre between not less than 12 radiologists with all four centres represented, reviewing all the films. Here if two or more radiologists correctly identify a lesion that subsequently proved malignant, the tumour is classified as a false negative.

Every effort is made to obtain a mammogram at the time of interval cancer presentation; should this prove positive and the original screening mammogram on review is negative, the lesion is classified as a true interval cancer, whereas a negative second mammogram defines an occult interval cancer. Unfortunately, if patients elect not to return to a screening centre a repeat mammogram may not be performed and distinction between a true and an occult interval cancer is not possible; these tumours are classified as interval cancer, not known. 
PATIENT SAMPLES

Three groups were compared; an interval cancer group, a screen detected group, and a symptomatic group.

Details of the first 112 interval cancers presenting to the unit were retrieved from the files of the Queen Elizabeth Hospital breast screening and assessment centre, forming the interval cancer group. The screen detected group was made up by matching each interval cancer with the patient detected by screening on the date nearest to that on which the interval cancer was diagnosed. The symptomatic group was formed by random selection from the histopathology files of 112 patients within the range of the other two groups. Although the age range set by the NHSBSP is $50-64$ years, 15 of the 336 patients fell outside this bracket, often because the interval cancers surfaced after the age of 64 . Six patients were older or younger than this extended limit, presenting for screening voluntarily, often because of a family history. However, the median range of all the groups was close.

\section{RADIOLOGY}

The mammograms were reviewed and abnormalities recorded using a slight modification of a classification already published. ${ }^{10}$ The categories were a well defined nodule, a poorly defined nodule or stellate lesion, microcalcification, deformity of architecture, and normal.

HISTOPATHOLOGY

All tumours were processed and diagnosed in accordance with the guidelines of the Royal College of Pathologists Working Group (1991).$^{11}$ All the cases, including those originally diagnosed outside the unit and the historical controls, were reviewed and graded by one of us (WKC).

NOTTINGHAM PROGNOSTIC INDEX This was calculated using the published method. ${ }^{12}$

IMMUNOHISTOPATHOLOGY

The monoclonal antibodies used are shown in table 1. For paraffin section immunohistochemistry, $5 \mu \mathrm{m}$ sections were cut from each paraffin block, mounted onto slides coated with Vectabond (Vector Laboratories), and dried overnight at $39^{\circ} \mathrm{C}$. Following 60 minutes drying at $60^{\circ} \mathrm{C}$, the sections were dewaxed, rehydrated, and treated with $\mathrm{H}_{2} \mathrm{O}_{2}$ /methanol for 10 minutes. The sections were then washed in running tap water for five minutes. Before the addition of the primary antibody, the high temperature antigen unmasking technique ${ }^{13}$ was employed for all antibodies except c-erbB2 . The dewaxed sections were first immersed in

Table 1 Immunohistochemistry: antibodies and dilutions

\begin{tabular}{llll}
\hline Antigen & Clone & Dilution & Source \\
\hline Oestrogen receptor & NCL-ER-6F11 & $1: 10$ & Novocastra \\
Progesterone receptor & NCL-PgR-1A6 & $1: 10$ & Novocastra \\
c-erbB-2 protein & NCL-CB11 & $1: 20$ & Novocastra \\
p53 protein & NCL-p53-DO7 & $1: 50$ & Novocastra \\
Ki67 protein & NCL-Ki67-MM1 & $1: 200$ & Novocastra \\
MDM2 protein & MDM2-Ab1 & $1: 150$ & Oncogene Science \\
\hline
\end{tabular}

$1 \mathrm{~mm}$ EDTA at $\mathrm{pH}$ 8.0. The sections were then covered with normal rabbit serum which had been diluted 1 in 5 with Tris buffered saline (NRS) and incubated for 10 minutes at room temperature in a humidified chamber. After removal of excess serum, appropriately diluted (table 1) primary antibody was added to the sections and incubated at $25^{\circ} \mathrm{C}$ for 30 minutes, with the exception of MDM2, for which overnight incubation at $4^{\circ} \mathrm{C}$ was employed. As a negative control, dNGS was added to a section and incubated as described. Sections were washed in Tris buffered saline for 10 minutes, changing the wash after five minutes. They were then incubated for 30 minutes with biotinylated rabbit antimouse immunoglobulins (NCL-GAMP, Novocastra Laboratories) diluted 1 in 500 with NRS. The sections were incubated for 30 minutes with avidinperoxidase at $25^{\circ} \mathrm{C}$. Following a further two five minute washes in Tris buffered saline, enzyme activity was revealed using a diaminobenzidine hydrochloride $/ \mathrm{H}_{2} \mathrm{O}_{2}$ substrate. For each antigen in every staining procedure a control section was included of a breast cancer of known strong expression of the relevant antigen.

SCORING METHOD

Tumours were scored on a subjective basis depending on the intensity of staining of tumour cells on a five point scale as follows: score $0=$ no labelling; score $+=$ weak labelling; score $++=$ moderate labelling; score $+++=$ strong labelling; score $++++=$ very intense labelling. Tumours with a score of + or greater were designated positive. In addition, the estimated proportion of cells stained positive was recorded, and for the purpose of analysis thresholds were chosen to divide the cases into "positive" or "negative" groups. For all antigens assessed, $0 \%$ and $10 \%$ thresholds were examined; in addition, for c-erbB-2 a $25 \%$ threshold for positivity was used. The latter additional threshold was examined because previous work by Wright et al has shown that this level is discriminant for better patient survival. ${ }^{14}$ Thus for each antigen an intensity and proportion score was recorded.

For all antigens the sections were screened by two independent observers (BA and SRAlT). Discrepant results were discussed over a double headed microscope and a final value agreed upon.

\section{STATISTICAL METHODS}

Fisher's exact test was used to test for associations between unordered categorical variables such as presentation of tumour and invasive type. Relations between ordered categorical variables (such as grade) and dichotomous variables (such as presence of vascular invasion) were investigated using a $\chi^{2}$ test for trend. Relations between size and dichotomous variables were investigated using a $t$ test; size does not follow a normal distribution so for the purposes of analysis the natural log of size was used. Estimates of median tumour size presented were determined by exponentiating the estimates of mean log tumour size. In the 
analysis of the immunohistochemistry the estimate of the amount of staining present was dichotomised according to standard practice, for example more than $25 \%$ staining if considered to be the standard cut off for c-erbB-2, while any staining is considered for p53. Multivariate logistic regression was used to investigate the relation between presentation of the tumour and protein staining adjusting for histological variables known to be related to protein staining. A forwards stepwise approach was used to identify the final model; a significance level of 0.05 was used to retain explanatory variables in the model.

\section{Results}

The "raw" interval cancer group was made up thus: true interval, 49 (44\%); occult, $8(7 \%)$; not known, 28 (25\%); false negatives, 27 $(24 \%)$.

In the analysis that follows the data from the false negatives have been removed.

\section{RADIOLOGY}

Only $40 \%$ of the symptomatic group had a mammogram. Microcalcification and deformity of architecture was found more commonly in the screen group. Although deformity of architecture was infrequent in the interval group, the data offer no credible radiological pattern characteristic of interval cancers as a group. However, within the occult interval cancers, lobular carcinoma-well known to be difficult to visualise mammographically-was significantly over-represented. Three of the eight occult cancers (38\%) were lobular, compared with $10 \%$ or less of other interval, screened, or symptomatic tumours.

PATHOLOGY

The findings are given in table 2 . There were significantly more in situ cancers in the screened group (24\%) than in either the symptomatic $(4 \%)$ or the interval cancer $(4 \%)$ groups. Of the invasive cancers, $11 \%$ of the screened group were tubular, contrasting with $1 \%$ of the symptomatic and $2 \%$ of the interval groups (Fisher's exact test, $\mathrm{p}=0.02$ ).

Differences in the size of tumours (including in situ lesions) were found. The median size of screen detected invasive cancers was $14.8 \mathrm{~mm}$, that of symptomatic tumours $22.4 \mathrm{~mm}$, and that of interval cancers $19.5 \mathrm{~mm}$. These figures are significant; not only were screen detected invasive tumours significantly smaller than the other two types, but interval cancers appeared to be smaller than symptomatic cancers $(\mathrm{p}=0.048)$.

There were significant differences in tumour grade between the groups: screen detected invasive lesions were of lower grade than either symptomatic or interval lesions; however, when interval cancers were compared with symptomatic cancers the interval group contained significantly fewer grade II tumours, with more grade I and grade III lesions.

The groups also differed significantly in terms of vascular invasion; invasion was present in $14 \%$ of invasive screen detected tumours, compared with $43 \%$ of symptomatic cancers and $34 \%$ of interval cancers. The difference between the last two groups is not significant.

Lymph node sampling was performed in $83 \%$ of the screened group, $77 \%$ of the symptomatic group, and $85 \%$ of the interval group. Of those that were sampled, positive lymph nodes were found in $30 \%$ of screen detected cancers, contrasting with $61 \%$ of symptomatic and $37 \%$ of interval cancers. The difference between interval cancers and screen detected cancers is not statistically significant.

Calculation of the Nottingham prognostic index implies that interval cancers had a worse prognosis than screen detected cancers but a better prognosis than symptomatic cancers.

\section{IMMUNOHISTOCHEMISTRY}

Table 3 summarises the results of immunohistochemical examination of the invasive tumours, recording the presence or absence of

Table 2 Histopathology results, excluding false negative interval cancers

\begin{tabular}{|c|c|c|c|c|c|c|}
\hline & & Screen detected & Symptomatic & Interval & False neg & Significance \\
\hline Age (years) & & 59 (48 to 66$)$ & 57 (49 to 67$)$ & 57 (35 to 72$)$ & $59(52$ to 70$)$ & \\
\hline In situ & & $27(24 \%)$ & $5(4 \%)$ & $3(4 \%)$ & 0 & \\
\hline Invasive & & $85(76 \%)$ & $107(96 \%)$ & $82(96 \%)$ & $27(100 \%)$ & $\mathrm{p}<0.0001$ \\
\hline Median size $(\mathrm{mm})^{\star}$ & & 14.8 & 22.4 & 19.5 & 22.0 & $\mathrm{p}<0.0001$ \\
\hline \multirow[t]{4}{*}{ Grade ${ }^{\star}$} & 1 & $38(45 \%)$ & $11(10 \%)$ & $19(23 \%)$ & $2(7 \%)$ & \\
\hline & 2 & $33(39 \%)$ & $51(48 \%)$ & $20(25 \%)$ & $9(33 \%)$ & \\
\hline & 3 & $14(16 \%)$ & $45(42 \%)$ & $42(51 \%)$ & $15(56 \%)$ & \\
\hline & Ungraded $\dagger$ & 0 & 0 & $1(1 \%)$ & $1(4 \%)$ & $\mathrm{p}<0.0001$ \\
\hline \multirow[t]{2}{*}{ Vascular invasion` } & Absent & $73(86 \%)$ & $61(57 \%)$ & $54(66 \%)$ & $14(52 \%)$ & \\
\hline & Present & $12(14 \%)$ & $46(43 \%)$ & $28(34 \%)$ & $13(48 \%)$ & $\mathrm{p}<0.0001$ \\
\hline \multirow{4}{*}{$\begin{array}{l}\text { Number of positive } \\
\text { lymph nodes }\end{array}$} & 0 & $50(59 \%)$ & $32(30 \%)$ & $44(54 \%)$ & $11(41 \%)$ & \\
\hline & $1-3$ & $14(16 \%)$ & $28(26 \%)$ & $18(22 \%)$ & $8(30 \%)$ & \\
\hline & $>3$ & $7(8 \%)$ & $22(21 \%)$ & $8(10 \%)$ & $3(11 \%)$ & \\
\hline & Not sampled & $14(16 \%)$ & $25(23 \%)$ & $12(15 \%)$ & $5(18 \%)$ & $\mathrm{p}=0.009$ \\
\hline \multirow[t]{4}{*}{ NPI* ${ }^{\star}$} & Good & $39(46 \%)$ & $11(10 \%)$ & $20(24 \%)$ & $3(11 \%)$ & \\
\hline & Moderate & $25(29 \%)$ & $43(40 \%)$ & $36(44 \%)$ & $13(48 \%)$ & \\
\hline & Poor & $7(8 \%)$ & $28(26 \%)$ & $14(17 \%)$ & $6(22 \%)$ & \\
\hline & Not calc & $14(17 \%)$ & $25(24 \%)$ & $12(15 \%)$ & $5(19 \%)$ & $\mathrm{p}<0.0001$ \\
\hline
\end{tabular}

Values are $\mathrm{n}(\%)$ or median (range)

$\star$ Invasive cancers only; †malignant phyllodes tumour; $¥$ Nottingham prognostic index

Calc, calculated; neg, negative. 
Table 3 Significant associations between immunohistochemical staining and other variables (invasive tumours)

\begin{tabular}{|c|c|c|c|c|c|c|}
\hline & $\begin{array}{l}\% \text { Cases } \\
\text { positive }\end{array}$ & Larger size & Higher grade & $\begin{array}{l}\text { Vascular } \\
\text { invasion }\end{array}$ & LN status & Presentation \\
\hline $\begin{array}{l}\mathrm{c}-e r b \mathrm{~B} 2 \\
25 \% \text { staining }\end{array}$ & 16.3 & $\begin{array}{l}\mathrm{p}=0.8 \\
\text { No }\end{array}$ & $\begin{array}{l}\mathrm{p}=0.003 \\
\text { Yes (+ve) }\end{array}$ & $\begin{array}{l}\mathrm{p}=0.01 \\
\text { Yes (+ve) }\end{array}$ & $\begin{array}{l}\mathrm{p}=0.9 \\
\text { No }\end{array}$ & $\begin{array}{l}\mathrm{p}=0.3 \\
\text { No }\end{array}$ \\
\hline $\begin{array}{l}\text { Any staining } \\
\text { p53 }\end{array}$ & 69.9 & $\begin{array}{l}\mathrm{p}=0.4 \\
\text { No }\end{array}$ & $\begin{array}{l}\mathrm{p}=0.4 \\
\text { No }\end{array}$ & $\begin{array}{l}\mathrm{p}=0.6 \\
\text { No }\end{array}$ & $\begin{array}{l}\mathrm{p}=0.4 \\
\text { No }\end{array}$ & $\begin{array}{l}\mathrm{p}=0.6 \\
\text { No }\end{array}$ \\
\hline $\begin{array}{l}\text { Any staining } \\
\text { Oestrogen recep }\end{array}$ & $\begin{array}{l}74.5 \\
\text { ptor }\end{array}$ & $\begin{array}{l}\mathrm{p}<0.001 \\
\text { Yes }(-\mathrm{ve})\end{array}$ & $\begin{array}{l}\mathrm{p}<0.001 \\
\text { Yes }(-\mathrm{ve})\end{array}$ & $\begin{array}{l}\mathrm{p}=0.047 \\
\text { Yes }(-\mathrm{ve})\end{array}$ & $\begin{array}{l}\mathrm{p}=0.9 \\
\text { No }\end{array}$ & $\begin{array}{l}\mathrm{p}=0.3 \\
\text { No }\end{array}$ \\
\hline $\begin{array}{l}\text { Any staining } \\
\text { Progesterone re }\end{array}$ & $\begin{array}{l}64.2 \\
\text { eceptor }\end{array}$ & $\begin{array}{l}\mathrm{p}<0.001 \\
\text { Yes (-ve) }\end{array}$ & $\begin{array}{l}\mathrm{p}<0.001 \\
\text { Yes }(-\mathrm{ve})\end{array}$ & $\begin{array}{l}\mathrm{p}=0.001 \\
\text { Yes }(-\mathrm{ve})\end{array}$ & $\begin{array}{l}\mathrm{p}=0.9 \\
\text { No }\end{array}$ & $\begin{array}{l}\mathrm{p}<0.001 \\
\text { Yes }\end{array}$ \\
\hline $\begin{array}{l}\text { Any staining } \\
\text { MDM2 }\end{array}$ & 39.4 & $\begin{array}{l}\mathrm{p}=0.7 \\
\text { No }\end{array}$ & $\begin{array}{l}\mathrm{p}=0.007 \\
\text { Yes }\end{array}$ & $\begin{array}{l}\mathrm{p}=0.4 \\
\text { No }\end{array}$ & $\begin{array}{l}\mathrm{p}=0.5 \\
\text { No }\end{array}$ & $\begin{array}{l}\mathrm{p}=0.5 \\
\text { No }\end{array}$ \\
\hline $\begin{array}{l}10 \% \text { staining } \\
\text { NM } 23\end{array}$ & 96.0 & $\begin{array}{l}\mathrm{p}=0.8 \\
\text { No }\end{array}$ & $\begin{array}{l}\mathrm{p}=0.8 \\
\text { No }\end{array}$ & $\begin{array}{l}\mathrm{p}=0.4 \\
\text { No }\end{array}$ & $\begin{array}{l}\mathrm{p}=0.7 \\
\text { No }\end{array}$ & $\begin{array}{l}p=0.2 \\
\text { No }\end{array}$ \\
\hline $\begin{array}{l}10 \% \text { staining } \\
\text { Ki67 }\end{array}$ & 46.0 & $\begin{array}{l}\mathrm{p}=0.002 \\
\text { Yes (+ve) }\end{array}$ & $\begin{array}{l}\mathrm{p}<0.001 \\
\text { Yes }(+\mathrm{ve})\end{array}$ & $\begin{array}{l}\mathrm{p}<0.001 \\
\text { Yes }\end{array}$ & $\begin{array}{l}\mathrm{p}=0.2 \\
\text { No }\end{array}$ & $\begin{array}{l}\mathrm{p}<0.001 \\
\text { Yes }\end{array}$ \\
\hline
\end{tabular}

LN, lymph node.

significant association between tumour size, grade, vascular invasion, lymph node status, and the presentation (screen detected, symptomatic, interval). Various predictable associations between the variables were noted-for example, hormone receptor positivity was inversely correlated with grade. Although the incidence of staining for MDM2 within grades of invasive tumours was significant, it was greatest within grade 2 lesions and hence this marker did not relate to grade in a meaningful way. With two exceptions, there were no significant associations between presentation and any of the markers studied. Screen detected tumours showed significantly more staining for PgR than the other groups, but there was no significant difference between interval and symptomatic cancers. However, taking a $10 \%$ cell staining threshold there were significant differences between the Ki67 index

Table 4 Influence of interval length (false negative interval cancers excluded)

\begin{tabular}{|c|c|c|c|c|c|c|c|c|}
\hline & & \multicolumn{6}{|c|}{ Length of interval (months) } & \multirow[b]{2}{*}{ Significance } \\
\hline & & \multicolumn{2}{|c|}{$0-12$} & \multicolumn{2}{|c|}{$13-24$} & \multicolumn{2}{|c|}{$25-36$} & \\
\hline In situ & & 3 & $(10 \%)$ & 0 & & 0 & & \\
\hline Invasive & & 28 & $(90 \%)$ & 31 & $(100 \%)$ & 23 & $(100 \%)$ & \\
\hline $\begin{array}{l}\text { Median size } \\
(\mathrm{mm})^{\star}\end{array}$ & & 18.9 & & 21.6 & & 17.7 & & $\mathrm{p}=0.3$ \\
\hline \multirow[t]{4}{*}{ Grade* } & 1 & 6 & $(21 \%)$ & 7 & $(23 \%)$ & 6 & $(26 \%)$ & \\
\hline & 2 & 5 & $(18 \%)$ & 9 & $(29 \%)$ & 6 & $(26 \%)$ & \\
\hline & 3 & 16 & $(57 \%)$ & 15 & $(48 \%)$ & 11 & $(48 \%)$ & \\
\hline & Ungraded $\dagger$ & 1 & $(4 \%)$ & 0 & & 0 & & $\mathrm{p}=0.8$ \\
\hline \multirow{2}{*}{$\begin{array}{l}\text { Vascular } \\
\text { invasion }{ }^{\star}\end{array}$} & Absent & 16 & $(57 \%)$ & 18 & $(58 \%)$ & 20 & $(87 \%)$ & \\
\hline & Present & 12 & $(43 \%)$ & 13 & $(42 \%)$ & 3 & $(13 \%)$ & $\mathrm{p}=0.04$ \\
\hline \multirow{4}{*}{$\begin{array}{c}\text { Number of } \\
\text { positive } \\
\text { lymph } \\
\text { nodes }^{\star}\end{array}$} & 0 & 18 & $(64 \%)$ & 15 & $(48 \%)$ & 11 & $(48 \%)$ & \\
\hline & $1-3$ & 5 & $(18 \%)$ & 10 & $(32 \%)$ & 3 & $(13 \%)$ & \\
\hline & $>3$ & 2 & $(7 \%)$ & 3 & $(10 \%)$ & 3 & $(13 \%)$ & \\
\hline & $\begin{array}{l}\text { Not } \\
\text { sampled }\end{array}$ & 3 & $(11 \%)$ & 3 & $(10 \%)$ & 6 & $(26 \%)$ & $\mathrm{p}=0.4$ \\
\hline \multirow[t]{4}{*}{ NPI $\ddagger$} & Good & 6 & $(21 \%)$ & 9 & $(29 \%)$ & 5 & $(22 \%)$ & \\
\hline & Moderate & 15 & $(54 \%)$ & 12 & $(39 \%)$ & 9 & $(39 \%)$ & \\
\hline & Poor & 4 & $(14 \%)$ & 7 & $(23 \%)$ & 3 & $(13 \%)$ & \\
\hline & Not calc & 3 & $(11 \%)$ & 3 & $(10 \%)$ & 6 & $(26 \%)$ & $\mathrm{p}=0.6$ \\
\hline
\end{tabular}

^Invasive cancers only; †malignant phyllodes tumour; $\neq$ Nottingham prognostic index. Calc, calculated. in the symptomatic, screened, and interval cancer groups.

LENGTH OF INTERVAL

The interval cancers were further assessed in terms of interval length (table 4). No relation was found between the length of interval and tumour size, grade, lymph node status, or prognostic index. However, patients presenting after shorter intervals were significantly more likely to suffer vascular invasion.

FALSE NEGATIVES

If the data from the false negative "interval" cancers are included, changes in the above results are slight and not significant.

\section{Discussion}

Wide differences between groups of workers over the definition of an interval cancer place severe restrictions on the comparison of various reports. Whereas some centres screen annually, ${ }^{215}$ others screen two yearly, ${ }^{16}{ }^{17}$ and in the NHSBSP the interval has been set at three years. Some investigators, as in the present series, accept as interval cancers only tumours presenting symptomatically, whereas others include cancers detected mammographically following early recall and some are not precise over the mode of presentation.

Within the NHSBSP some groups choose to exclude in situ disease ${ }^{18}{ }^{19}$; another excludes ductal carcinoma in situ, ${ }^{20}$ and $\mathrm{Guy}^{21}$ has suggested exclusion of second primaries. In a plea for standardisation throughout the NHSBSP, Duncan and Wallis ${ }^{22}$ have demonstrated significant discrepancies of radiological control; within the service, diagnosis of interval cancers follows reassessment by a range of one to 14 radiologists who may or may not review the mammograms mixed with normal screening films. These authors recommend at least three external reviewers.

Currently mammography of symptomatic cases is more common than in this series and awareness of interval cancers has much reduced our numbers in the "not known" category.

Assembling a symptomatic control group is difficult. In our unit few patients within the NHSBSP age range now present symptomatically and of those who do some will be "refusers and lapsed attenders" who, with known worse prognosis, might introduce bias. Cases were therefore selected totally at random from historical files, accepting that these women might have presented later than the interval patients. Hence, however selected, symptomatic tumours may carry a bias towards poorer prognosis.

However high the standard of mammographic screening, restrospective analysis will detect some lapses. In our region, Jones et al compared the mammograms of cancers diagnosed at second or subsequent rounds of screening with the first films and concluded that some lesions may have been present originally. ${ }^{23}$ The diagnostic criteria for an interval cancer within the Northern Region are unusually strict and it is tempting to suggest 
that lesions classified as false negatives might be regarded as true interval cancers elsewhere. But despite these considerations, our false negative rate is low, at $27 / 112(24 \%)$.

Our painstaking process of classifying interval cancers may be related to the finding that the inclusion or exclusion of the false negative data does not substantially alter the significance of the results. Compared with true interval cancers, von Rosen et al found fewer lymph node positive tumours in their "unrecognised" and "observer error" groups of interval cancers, although the "unrecognised" tended to be of higher grade. ${ }^{24}$ Frisell et al found no difference in survival between true interval cancers and false negative cases. ${ }^{25}$ Our findings are compatible with this but it would be ill judged to deduce from them that tumours presenting in the interval after a missed mammographic diagnosis are not different from true interval cancers. Although any differences between the two categories lack statistical significance, analysis suggests that our false negative cancers are closer to our symptomatic tumours than true interval cancers in terms of size and grade-divergences that one might anticipate. But further reduction of the false negative rate and improvement of the prognosis of these patients from that of interval cancer to that of screen detected cancer would necessitate the needless recall and biopsy of very many women.

We have found that compared with both symptomatic and interval cancers, screen detected tumours are more likely to be in situ, and if invasive, to be smaller, of lower grade, to have less vascular invasion and fewer positive lymph nodes, and a greater likelihood of being tubular. These features of screened versus symptomatic breast lesions are well established ${ }^{26-28}$ and are to be expected. Of the three in situ tumours in the interval group, two presented with nipple discharge and one with Paget's disease.

Patients with interval cancers, like those in our symptomatic group, present clinically, yet their tumours were somewhat smaller. Peeters et al observed the same size difference; the likely explanation is that those in the interval group, having already been through an episode of screening, are more "breast aware" than the symptomatic group. ${ }^{16}$

Less easy to explain when comparing interval and symptomatic tumours is the relative preponderance of grade I and III lesions in the interval group. Their smaller size might contribute to the grade I element but the finding does not support the belief that interval cancers are all aggressive neoplasms. DeGroote et $a l^{1}$ felt that these tumours were indeed aggressive lesions but their opinion was contradicted and criticised by Holmberg et al. ${ }^{29}$ Von Rosen et al concluded that interval cancers were a heterogeneous group including some tumours of low malignancy potential, and our data are in agreement. ${ }^{24}$

Vascular invasion correlated with lymph node status in all three study groups and this is to be expected; Ørbu et al emphasised this strong connection. ${ }^{30}$ Comparing the frequency of both vascular invasion and lymph node positivity in the three study groups, interval cancers are more likely to be positive than screened cancers but less likely than symptomatic tumours. This is in parallel with the distribution of tumour size and is in accordance with the established relation of size to lymph node status. $^{31}$

Several groups have studied survival of patients with interval cancers. The Malmö experience is exceptional in finding poorer survival than in symptomatic controls. ${ }^{32}$ In contrast, survival was found to be similar to that of symptomatic cancers by Shapiro et al, ${ }^{33}$ Holmberg et $a l,{ }^{29}$ Peeters et $a l,{ }^{16}$ Koivunen et $a l,{ }^{2}$ Brekelmans et $a l,{ }^{34}$ and within the NHSBSP by Collins et al. ${ }^{35}$ Frisell et al reported longer survival of patients with interval cancer compared with symptomatic cases. ${ }^{25}$ Our finding of a prognostic index intermediate between screened and symptomatic tumours mirrors the survival data of Schroën et al. ${ }^{36}$ There is, in short, little evidence that interval cancers as a group carry an especially poor prognosis and that presentation between screening episodes necessarily connotes an aggressive neoplasm. The contrary view of DeGroote et al, ${ }^{1}$ still cited and held, can hardly be sustained.

If survival of patients with interval cancers is no worse than other symptomatic cancers, this must be reconciled with the view that a proportion of interval cancers must be relatively fast growing. ${ }^{17}$ A partial explanation could be that any sample of symptomatic cancers will contain some that are fast growing. Alternatively or additionally, rapid growth may not imply worse prognosis, a possibility mooted by Holmberg et al. ${ }^{37}$ If tumour size is a major factor determining $\operatorname{grade}^{26}$ or lymph node involvement, ${ }^{31}$ then little difference between survival of interval and symptomatic cancers is to be expected.

There have been few immunohistochemical studies of interval cancers. Koivunen et $a l^{2}{ }^{2}$ employing a variety of markers, concluded that the results did not suggest biological aggression of these tumours but there were no direct control groups. Peeters et al found similar oestrogen receptor positivity in true interval cancers and symptomatic cancers but higher rates in screened patients, ${ }^{16}$ whereas Brekelmans et al, ${ }^{34}$ as in the present series, detected no statistical differences in oestrogen receptor positivity in any of these three groups. Comparing screen detected and symptomatic tumours, our immunohistochemical results replicate earlier work $^{28}$ in respect of markers common to both studies. Our finding that staining by Ki67 discriminates between screened, interval, and symptomatic tumours is of some interest. Logistic regression shows that the discrimination cannot be explained by grade, and demonstrates for example that a grade 3 interval cancer is five times more likely to show a high Ki67 index than a grade 3 screen detected cancer.

Our demonstration that the length of interval is independent of tumour size, grade, and lymph node status is at variance with the accepted view that more aggressive, rapidly 
growing tumours will surface earlier. But with few exceptions interval cancers present when the patient becomes aware of a mass; it is the size of the mass irrespective of grade that determines the point of diagnosis. It may be that it is this tendency to uniform size (which relates to grade and lymph node status) that is responsible for the lack of correlation with interval length. One might have expected to find an increase in higher grade cancers in the early presenters; we have not, and although we have shown a significant increase in vascular invasion in this subset, the general uniformity of data within the interval lengths is supported by Frisell et $a l^{25}$ who found no correlation between interval length and survival.

The distribution of the tumours within the interval lengths calls for comment. The general experience is that the incidence of interval cancer tends to rise with increasing interval; within the NHSBSP, Woodman et $a l^{38}$ found $20 \%$, $32 \%$, and $49 \%$ in the first, second, and third years, respectively, and this rising incidence has been seen elsewhere. ${ }^{39}$ The different pattern in our series derives from the nature of the patient sample which is taken from the start of our screening programme and which therefore contains a disproportionate number of women whose interval cancers presented before they could have been observed for three years. It is of interest, however, that the majority of interval cancers in the first year are of the "unknown" category, suggesting perhaps that early presentation prompts the patient to seek advice elsewhere.

The study most closely comparable to the present series is that of Burrell et $a l,{ }^{40}$ a comprehensive review of interval cancers presenting within the NHSBSP. Our results are in some measure a replication, but differ in placing interval cancers between screen detected and symptomatic rather than suggesting that they are essentially similar to symptomatic tumours. The Nottingham symptomatic control group is substantially larger than the Gateshead group, and further study may reconcile this difference. But the clear message from both series is that the prognosis of interval cancers within the NHSBSP is in general no worse than that of symptomatic disease.

Our data indicate that interval cancers diagnosed after strict radiological control are intermediate between screen detected and symptomatic tumours in respect of size, vessel invasion, lymph node status, and prognosis, and that these features remain constant irrespective of the interval length. The view that these tumours are in general highly malignant is invalidated, but an excess of grade 3 cancers and tumours with a high Ki67 index suggests that within a heterogeneous sample a minority are indeed unusually aggressive.

1 DeGroote R, Rush BF, Milazzo J, et al. Interval breast cancer: a more aggressive subset of breast neoplasias. Surgery 1983;94:543-7.

2 Koivunen D, Zhang X, Blackwell C, et al. Interval breast cancers are not biologically distinct-just more difficult to diagnose. Am F Surg 1994;169:538-42. 3 Quénel $\mathrm{N}$, Wafflart J, Bonichon $\mathrm{F}$, et al. The prognostic
value of $\mathrm{c}-e r b \mathrm{~B}-2$ in primary breast carcinomas: a study of value of c-erbB-2 in primary breast carcinomas: a

4 Osborne CK. Steroid hormone receptors in breast cancer management. Breast Cancer Res Treat 1998;51:227-38.

5 Albertazzi E, Cajone F, Leone BE, et al. Expression of metastasis-associated genes $h$-mts (S100A4) and $n m 23$ in carcinoma of breast is related to disease progression. DNA Cell Biol 1998;17:335-42.

6 Page DL, Jensen RA, Simpson JF. Routinely available indicators of prognosis in breast cancer. Breast Cancer Res Treat 1998;51:195-208.

7 Bosari S, Viale G. The clinical significance of p53 aberrations in human tumours. Virchows Arch 1995;427: 229-41.

8 O'Neill M, Campbell SJ, Save V, et al. An immunochemical analysis of $\mathrm{mdm} 2$ expression in human breast cancer and the identification of a growth-regulated cross-reacting species p170. F Pathol 1998;186:254-61.

9 Simpson W, Neilson F, Young JR. The identification of false negatives in a population of interval cancers: a method for audit of screening mammography. Breast 1995;4: 183-8.

10 Lunt LG, Cowan WK, Cunliffe WJ, et al. Too many biopsies: correlation of radiological assessment with biopsy findings in a prevalent screening programme. Eur f Oncol 1991;17:107-8.

11 Royal College of Pathologists Working Group. Pathology reporting in breast cancer screening. F Clin Pathol 1991;44: $710-25$.

12 Haybittle JL, Blamey RW, Elston CW, et al. A prognostic index in primary breast cancer. $\mathrm{Br} \mathcal{F}$ Cancer 1982;45: 361-6.

13 Shi SR, Key ME, Kalra KL. Antigen retrieval in formalin fixed paraffin embedded tissues: an enhancement method for immunohistochemical staining based on microwave oven heating of tissue sections. F Histochem Cytochem 1991; 39:741-8.

14 Wright C, Angus B, Nicholson S, et al. Expression of c-erbB-2 oncoprotein; a prognostic indicator in human breast cancer. Cancer Res 1989;49:2087-90.

15 Burhenne HJ, Burhenne LW, Goldberg F, et al. Interval breast cancers in the screening mammography program of British Columbia: analysis and classification. Am 7 Roentgenol 1994;162:1067-71.

16 Peeters PHM, Verbeek ALM, Hendriks JHCL, et al. The occurrence of interval cancers in the Nijmegen screening programme. Br f Cancer 1989;59:929-32.

17 Brekelmans CT, van Gorp JM, Peeters PH, et al. Histopathology and growth rate of interval breast carcinoma. Cancer 1996;78:1220-8.

18 Day N, McCann J, Camilleri-Ferrante C, et al. Monitoring interval cancers in breast screening programmes: the East Anglian experience. 7 Med Screen 1995;2:180-5.

19 Faux AM, Richardson DC, Lawrence GM, et al. Interval breast cancers in the NHS Breast Screening Programme: does the current definition exclude too many? F Med Screen 1997;4:169-73.

20 Sylvester PA, Vipond MN, Kutt E, et al. Rate and classification of intervals cancers in the breast screening classification of intervals cancers in the breast screc
programme. Ann R Coll Surg Engl 1997;79:276-7.

21 Guy M. Guidelines for the identification of interval breast cancers. NHSBSP, East Anglian Regional Health Authority, 1991

22 Duncan AA, Wallis MG. Classifying interval cancers. Clin Radiol 1995;50:774-7.

23 Jones RD, McLean L, Young JR, et al. Proportion of cancers detected at the first incident screen which were false negative at the prevalent screen. Breast 1996;5:339-43.

24 von Rosen A, Erhardt K, Hellström L, et al. Assessment of malignancy potential in so-called interval mammary carcinomas. Breast Cancer Res Treat 1985;6:221-7.

25 Frisell J, von Rosen A, Wiege M, et al. Interval cancer and survival in a randomized breast cancer screening trial in survival in a randomized breast cancer screening
Stockholm. Breast Cancer Res Treat 1992;24:11-16.

26 Duffy SW, Tabar L, Fagerberg G, et al. Breast screening, prognostic factors and survival-results from the Swedish two county study. Br f Cancer 1991;64:1133-8.

27 Anderson TJ, Lamb J, Donnan P, et al. Comparative pathology of breast cancer in a randomised trial of screening. $\mathrm{BrF}$ Cancer 1991;64:108-13.

28 Cowan WK, Kelly P, Sawan A, et al. The pathological and biological nature of screen-detected breast carcinomas: a morphological and immunohistochemical study. $\mathcal{F}$ Pathol 1997;182:29-35.

29 Holmberg LH, Tabar L, Adami HO, et al. Survival in breast cancer diagnosed between mammographic screening examinations. Lancet 1986;ii:27-30.

30 Ørbo A, Stalsberg H, Kunde D. Topographic criteria in the diagnosis of tumor emboli in intramammary lymphatics. Cancer 1990;66:972-7.

31 Carter CL, Allen C, Henson DE. Relation to tumor size, ymph node status, and survival in 24,740 breast cancer cases. Cancer 1989;63:181-7.

32 Andersson I, Aspegren K, Janzon L, et al. Mammographic screening and mortality from breast cancer: the Malmö mammographic screening trial. BMF 1988;297:943-8.

33 Shapiro S, Venet W, Strax P, et al. Ten- to fourteen-year effect of screening on breast cancer mortality. $\mathcal{F}$ Natl Cancer Inst 1982;69:349-55.

34 Brekelmans CT, Peeters PH, Deurenberg JJ, et al. Survival in interval breast cancer in the DOM screening programme. Eur F Cancer 1995;31A:1830-5. 
35 Collins S, Woodman CBJ, Threlfall A, et al. Survival rates from interval cancer in NHS breast screening programme. BMF 1998:316:832-3.

36 Schroën AA, Wobbes T, van der Sluis RF. Interval carcinomas of the breast: a group with intermediate outcome. $f$ Surg Oncol 1996;63:141-4.

37 Holmberg L, Pontén J, Adami H-O. The biology and natural history of breast cancer from the screening perspective. World $\mathcal{F}$ Surg 1989;13:25-30.

38 Woodman CBJ, Threlfall AG, Boggis CRM, et al. Is the three year breast screening interval too long? Occur- rence of interval cancers in NHS breast screening programme's north western region. BMF 1995;310: 224-6.

39 Tabár L, Faberberg G, Day NE, et al. What is the optimum interval between mammographic screening examinations? -An analysis based on the latest results of the Swedish two-county breast cancer screening trial. Br F Cancer 1987; 55:547-51.

40 Burrell HC, Sibbering DM, Wilson ARM, et al. Screening interval breast cancers: mammographic features and prognostic factors. Radiology 1996;199:811-17.

\section{Foundations}

\section{On pathologists ....}

This is the reason that such craftsmen hardly ever escape that weakness of vision called myopia. Moreover, since the eyes are continually kept on the work, intent and immobile, the humors thicken and lose simultaneously their fluidity and transparency; thus weakness of vision gradually develops in these craftsmen; and so, even those who have been endowed by nature with good sharp eyes become in time myopic and purblind.

Chapter XXXVII: Diseases of those who do fine work. De Morbis Artificium (Diseases of Workers), by Bernadini Ramazzini (from the Latin text of 1713) 